\section{PATENT WATCH}

\section{Augmentin' the battle}

Earlier this year, the three remaining patents protecting GlaxoSmithKline's (GSK) blockbuster antibiotic augmentin were invalidated by a US Federal District Court ruling, in favour of generic drug manufacturers Geneva Pharmaceuticals, Teva Pharmaceuticals and Ranbaxy. In an unusual twist to the case, GSK filed lawsuits against these generics companies, accusing them of using a stolen strain of the bacteria, which it claims is a trade secret. The bacterium is used to produce potassium clavulanate, which, in combination with the antibiotic amoxycillin, makes up augmentin. GSK claims that one of its former employees allegedly stole the bacterium, although it does not accuse the defendants of being involved in the theft. Although such cases are notoriously difficult to prove, the US International Trade Commission has accepted the case, the first since 1984. The companies that are being sued claim that the charges are unfounded. Notwithstanding the case concerning alleged abuse of trade secrets, GSK still believes its augmentin patents are valid, and the company plans to appeal the rulings that invalidated the patents. Geneva has already received final approval from the US Food and Drug Administration for its version of the drug, so generic versions of augmentin might be available in the United States by the end of this year. GSK plans to pursue damages to recover lost profits if any generic drugs are introduced before a successful appeal.

\section{WEB SITE}

US Patent and Trademark Office: http://www.uspto.gov/

Cole, M., Howarth, T. T. \& Reading, C. Antibiotics. US Patent 4,525,352 (1981) | Cole, M., Howarth, T. T. \& Reading, C. Antibiotic from Streptomyces clavulicerus. US Patent 4,529,720 (1981) | Cole, M.. Howarth, T. T. \& Reading, C. Antibiotics. US Patent 4,560,552 (1981)

\section{Anticipating transgenic mice}

Can transgenic animals incorporating mutant transgenes be patented despite earlier disclosure of the genetic mutation and an earlier suggestion that the mutation could be used to create a transgenic animal by generally known techniques? In its 30 August 2002 decision, Elan Pharmaceuticals, Inc. v. Mayo Foundation For Medical Education and Research, the US Court of Appeals for the Federal Circuit reversed a judgement by a lower court that invalidated two patents of Elan-Athena Neurosciences, claiming rodents that were transgenic for the Swedish mutation of the human amyloid- $\beta$ precursor protein (APP), which might cause Alzheimer's disease. Elan's claims further required that the patented transgenic rodent could produce sufficient levels of activating transcription factor (ATF)-APP to be detectable in a brain homogenate. The District Court had come to its decision after observing that an earlier-filed patent by Mullen had discussed the possibility of creating transgenic animals based on the Swedish mutation of APP. The lower court reasoned that the remaining characteristics of Elan's claimed transgenic mouse would have been inherently recognized in the Mullen disclosure patent by those skilled in the art at the time that the Mullen patent was filed. In its appeal, Elan argued that Mullen's disclosure was not sufficient to anticipate Elan's invention either explicitly or inherently, because ATF-APP had not been disclosed in humans until after the Mullan patent was filed, and so would not have been recognized as inherent within Mullan's disclosure at that time. In a two-to-one decision, the Federal Circuit Appeals Court agreed with Elan and remanded the case back to the lower court for further proceedings. It seems, therefore, that the prior patenting of a genetic mutation, coupled with generalized suggestions of creating transgenic animals, does not necessarily rule out the possibility of others subsequently developing and patenting a transgenic animal.

US Patent and Trademark Office: http://www.uspto.gov/

Mullan, M. J. Nucleic acids for diagnosing and modeling Alzheimer's disease. US Patent 5,455,169 (1995)

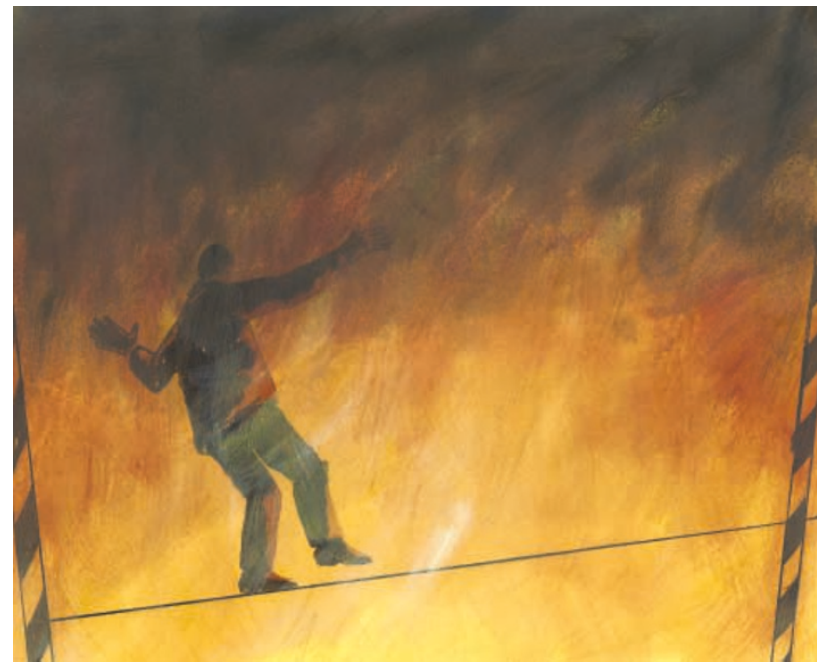

ANTICOAGULANTS

\section{Balance control}

The use of anticoagulant drugs can cause acute complications, such as significant bleeding. So, despite limitations, such as a narrow therapeutic window, heparin is still a mainstay of current anticoagulant therapy because its actions can be reversed by using protamine, in contrast to other commonly used drugs, such as warfarin. Now, by selecting aptamers - single-stranded nucleic acids that can fold into intricate globular structures for their ability to bind specifically to a procoagulant protein, Rusconi et al. have created an aptamer with anticoagulant effects that can be rapidly reversed using a rationally designed oligonucleotide 'antidote'.

The authors chose coagulation factor IXa (FIXa) as the target for aptamer generation, as animal studies had indicated that inhibitors of this protein might have a particularly favourable therapeutic window. Aptamers were created against FIXa using well-established techniques, and were assessed for their selectivity over several structurally similar proteins involved in the regulation of blood coagulation, including activated protein $\mathrm{C}$, for which inhibition would promote blood coagulation. An aptamer with 5,000-fold selectivity for FIXa was identified, and in vitro plasmaclotting assays showed that it could inhibit FIXa activity in human plasma. Importantly for the potential clinical usefulness of such aptamers, attachment of a polyethylene-glycol chain to one end of the aptamer - a modification that considerably enhances its bioavailability - did not influence the anticoagulant activity of the aptamer significantly.

How could an antidote to this aptamer be produced? Aptamers fold into their globular structures through the formation of internal base pairs. So, the authors designed a series of oligonucleotides to compete for the crucial base pairs of the anticoagulant aptamer with the aim of disrupting its threedimensional structure and thus its ability to bind to its target. Tests with human plasma showed that the oligonucleotides could rapidly reverse the effects of the anticoagulant aptamer, with their effectiveness being directly correlated with their ability to bind to the aptamer.

Translation of these promising in vitro results into in vivo animal models is eagerly awaited. And, in general, the development of aptamer-antidote pairs could prove particularly valuable for indications in which the acute side effects of treatment might lead to increased morbidity and mortality.

(2) References and links Peter Kirkpatrick ORIGINAL RESEARCH PAPER Rusconi, C. P. et al. RNA aptamers as reversible antagonists of coagulation factor IXa. Nature 419, 90-94 (2002) 